\title{
A Study of Brainwave Entrainment Based on EEG Brain Dynamics
}

\author{
Tianbao Zhuang \\ School of Educational Technology, Shenyang Normal University \\ Shenyang 110034, China \\ E-mail: bfztb@sina.com
}

Hong Zhao

Graduate School of Innovative Life Science

University of Toyama

Toyama, Japan

Tel: 81-090-3886-9168_E-mail: zam658@sina.com

\author{
Zheng Tang \\ Faculty of Engineering \\ University of Toyama \\ Toyama, Japan \\ E-mail: ztang@eng.u-toyama.ac.jp
}

\begin{abstract}
The brain which is composed of more than 100 billion nerve cells is a sophisticated biochemical factory. For many years, neurologists, psychotherapists, researchers, and other health care professionals have studied the human brain. With the development of computer and information technology, it makes brain complex spectrum analysis to be possible and opens a highlight field for the study of brain science. In the present work, observation and exploring study of the activities of brain under brainwave music stimulus are systemically made by experimental and spectrum analysis technology. From our results, the power of the $10.5 \mathrm{~Hz}$ brainwave appears in the experimental figures, it was proved that upper alpha band is entrained under the special brainwave music. According to the Mozart effect and the analysis of improving memory performance, the results confirm that upper alpha band is indeed related to the improvement of learning efficiency.
\end{abstract}

Keywords: Brainwave, Entrainment, EEG, Alpha

\section{Introduction}

The brain which is composed of more than 100 billion nerve cells is a sophisticated biochemical factory.For many years, neurologists, psychotherapists, researchers, and other health care professionals have studied the human brain.

They had long believed that brain activity such as brain waves and secretion of brain chemicals were beyond conscious control. But, experiments on Swami Rama of the Himalayas and on biofeedback had changed that belief. It was proven that some people can control their brain waves, etc. A ceaseless shenelectro-chemical activity exists at all times within the brain, and it can be detected on the scalp by using sensitive electronic instruments. Scientists have recorded and classified according to wave shapes and rhythm many different electrical waveforms associated with different kinds of mental activity.

One commonly studied parameter is the electrical activity of the brain. Using electrodes adhered to a person's scalp in conjunction with associated electronics (amplifiers, filters, etc.), an electroencephalogram ("EEG") is recorded over a given time period depicting the electrical activity of the brain at the various electrode sites. In general, EEG signals (colloquially referred to as "brainwaves") have been studied in an effort to determine relationships between frequencies of electrical activity or neural discharge patterns of the brain and corresponding mental, emotional and cognitive states. 
The Cerebral Cortex directs the brain's higher cognitive and emotional functions. It is divided into two almost symmetrical halves called the cerebral hemispheres. Each hemisphere contains four lobes. Areas within these lobes oversee all forms of conscious experience, including perception, emotion, thought, and planning, as well as many unconscious cognitive and emotional processes.

The Frontal Lobe assists in motor control and cognitive activities, such as planning, making decisions, setting goals, and relating the present to the future through purposeful behavior. The Parietal Lobe assists in sensory processes, spatial interpretation, attention, and language comprehension. The Occipital Lobe processes visual information and passes its conclusions to the parietal and temporal lobes. The Temporal Lobe assists in auditory perception, language comprehension, and visual recognition. (Table 1)

Scientists have discovered that our brainwaves are of five types. The number of times the peak appears in one second is named "frequency".To some degree, these frequency bands are a matter of nomenclature (i.e., any rhythmic activity between $8-12 \mathrm{~Hz}$ can be described as alpha), but these designations arose because rhythmic activity within a certain frequency range was noted to have a certain distribution over the scalp or a certain biological significance. There are five categories of these brainwaves, ranging from the least activity to the most activity: delta $(0-4 \mathrm{~Hz})$, theta $(4-8 \mathrm{~Hz})$, alpha $(8-12 \mathrm{~Hz})$, beta $(12-25 \mathrm{~Hz})$ and gamma $(25-100 \mathrm{~Hz})$. (Table 2)

\section{Brainwave Entrainment}

\subsection{The Concept of Brainwave Entrainment}

First, let us to see what is Entrainment. Generally speaking, Entrainment is the process whereby two interacting oscillating systems, which have different periods when they function independently, assume the same period. The two oscillators may fall into synchrony. In other words, Entrainment is the synchronization of a biological rhythm and an environmental cue (Michelle L. Johnson, online).

Brainwave Entrainment refers to the brain's electrical response to rhythmic sensory stimulation, such as pulses of sound or light. When the brain is given a stimulus, through the ears, eyes or other senses, it emits an electrical charge in response, called a Cortical Evoked Response. These electrical responses travel throughout the brain to become what you see and hear. This activity can be measured using sensitive electrodes attached to the scalp.

An interesting example is that when you hold a tuning fork that is tuned to the frequency of a $G$ note. Strike the tuning fork and place it near a guitar and you will notice that the $G$ string on the guitar starts to vibrate. This phenomenon indicates that the guitar has entrained on the tuning forks frequency.

How does this have anything to do with the brain? It actually has a lot to do with the brain when you realize that the brain is pulsing with electrical impulses. This electrical activity can be measured with a piece of equipment EEG, which measures the frequency of the electrical current. This frequency or speed of the brainwaves is measured in Hertz (Hz). Now here is the really cool part - the predominant frequency that your brain is resonating with at any particular moment can be associated with your state of mind. This means that your state of mind, for example relaxed, frightened, or sleepy can be seen in your brainwave frequencies at that moment.

Yogis spend years practicing meditation techniques to learn to induce deep states of meditation. The main techniques they have used to be able to achieve these deep states of mind is spending time in dedicated practice hours of practice every day. They work diligently quieting their mind and coaxing their brain into the different states. In today's world few people can tell their wives and children that they are going to sit and meditate for three hours, so please be quiet. We can all experience the amazing benefits of Brainwave Entrainment by listening special brainwave music. The music will enable you to achieve these same states in a just few sessions.

Perceptual entrainment comes in two forms. Several authors observed 'symmetrical' (or 'bidirectional') entrainment, i.e., two systems mutually influence each other when subjects are asked to synchronize their leg or index finger movements with that of another person (Schmidt, Carello and Turvey, 1990; Kelso, 1995). However, symmetrical entrainment has also been reported in contexts where participants are not asked to synchronize (Shockley et al., 2003; Richardson et al., 2007). Additionally, there is evidence for 'uni-directional' entrainment, i.e., a robust external oscillator influences a system, but nor vice versa. This has been shown in studies investigating brainwave synchronization following rhythmic stimulation, i.e., entrainment to periodic acoustic stimuli (Will and Berg, 2007).

\subsection{The Benefits of Brainwave Entrainment}

There are a few of the benefits you can experience with Brainwave Entrainment.

a. Increase your focus and concentration.

b. Increased memory performance.

c. Increased creativity and problem solving ability.

d. Enhanced sleep and ease of getting to sleep. 
e. Enhanced health.

f. Access your intuition.

g. Relaxation and stress reduction.

h. Behavior modification (getting rid of your bad habits).

In the above benefits, 1,2 and 3 is rated to the learning efficiency. When your brain is brought into an alpha or delta state by Brainwave Entrainment, you will find that you have improved your learning abilities.

There are studies that say most of all sickness is strongly linked to stress. Stress causes chemical changes in the brain which in turn affect your health. By using Brainwave Entrainment to change the state that your brain is in, you can affect your health in a positive manner. Just by bringing your brain into an alpha state you will find that your stress melts away and your outlook on life brightens. I do want to mention that diet and exercise is also crucial to reducing stress and you will find that you can use Brainwave Entrainment to help program your mind to change your diet and get you to exercise. The benefits to be realized by controlling your brainwaves are wonderful. You may be thinking, Brainwave Entrainment is similar in the sense that you will find over time you will be able to handle stress and life's issues more easily.

\section{Experimental Design and method}

\subsection{Subjects}

A sample of 12 right handed students ( 6 males and 6 females) participated in the experiment. Their mean age was 24.5 years. Before participating in the experiment, subjects were asked about the hand they use in different tasks such as handwriting, throwing a ball, etc. A subject was considered right-handed if he/she indicated to use the right hand for all of these different tasks.

\subsection{Design}

Subjects had to listen to the brainwave music at least 15 minutes with the headphone; at the whole process, their eyes keep closed. Each subject was tested under all of the experimental conditions.

\subsection{Apparatus}

EEG-signals were amplified by a 64-channel biosemi system (frequency response: 0.15 to $30 \mathrm{~Hz}$ ), subjected to an anti-aliasing filterbank (cut-off frequency: $30 \mathrm{~Hz}, 110 \mathrm{~dB}$ /octave) and were then converted to a digital format via a 64-channel A/D converter. Sampling rate was $512 \mathrm{~Hz}$. During data acquisition, EEG signals were displayed online on a high resolution monitor and stored on disk.

\subsection{Recordings}

A set of 64 silver electrodes, attached with a glue paste to the scalp was used to record EEG-signals [Fig.1]. A mid-forehead electrode was the ground. The horizontal and vertical EOG was registered simultaneously. EEG data contaminated with artifact were visually detected and rejected off-line. On average, $30 \%$ of trials were rejected due to artifacts. Remaining EEG data were corrected for eye movements using a linear regression method (D.J.L.G. Schutter and J. van Honk,2005). Two ear lobe electrodes (termed A1 and A2), were attached to the left and right ear. The EOG was recorded from 2 pairs of leads in order to register horizontal and vertical eye movements.

\subsection{Procedure}

Following electrode placement and instrument calibration, the subject was seated in a chair in the registration room and the experimental procedure was explained. The subject was instructed to assume a comfortable position and to avoid movement. Following this, the subject was instructed to look forward and to relax. EEG data were gathered for a 5 min period pre-experimental reference. After this, the researcher entered the registration room to give the subject final instructions. The subject was told to look forward, listen to the brainwave music stimulation. EEG data were gathered for $15 \mathrm{~min}$ for each experimental condition. After that, EEG data were gathered for a 5 min period post-experimental reference.

\section{Results}

This shows that the forebrain should possibly be more active than the hindbrain for the brainwave music stimulus. [Fig.2]

Each colored trace represents the spectrum of the activity of one data channel. The leftmost scalp map shows the scalp distribution of power at $5.5 \mathrm{~Hz}$, which in these data is concentrated on the frontal midline. The other scalp maps indicate the distribution of power at $10.5 \mathrm{~Hz}$ and $20.5 \mathrm{~Hz}$.

The plot below shows that alpha band power (e.g., at $10.5 \mathrm{~Hz}$ ) is concentrated over the central temporal scalp. There is a peak at about $10.5 \mathrm{~Hz}$ in this plot, which indicates that the upper alpha rhythm was entrained under the brainwave 
music stimuli.

We measured the details of ERP spectrum within one second as shown in [Fig. 3].The spectra were recorded in an interval time of $50 \mathrm{~ms}$ within extending one second after the auditory stimulus happens.

Here, the states of the brainwave come from the brainwave music stimulus. It can be seen that the color difference between the heavy blue and deep red appears after $200 \mathrm{~ms}$, it is the strongest after $450 \mathrm{~ms}$.

This shows that, within the first second, the strong brain activity appears after $200 \mathrm{~ms}$ and the strongest activity is between $400-450 \mathrm{~ms}$. This strong activity keeps a standing time of $250 \mathrm{~ms}$ about.

In the window, we plotted the spectra of each component [Fig. 4]. A more accurate strategy (for technical reasons) is to plot the data signal minus the component activity and estimate the decrease in power in comparison to the original signal at one channel (it is also possible to do it at all channel but it requires to compute the spectrum of the projection of each component at each channel which is computationally intensive). It is to plot component's contribution at channel (FT7) where power appears to be maximum at $10.5 \mathrm{~Hz}$.

\section{References}

D.J.L.G. Schutter and J. van Honk, Salivary cortisol levels and the coupling of midfrontal delta-beta oscillations, Int. J. Psychophysiol. 55 (2005). pp. 127-129.

Kelso, J., (1995). Dynamic patterns. MIT Press, Cambridge.

Michelle L. Johnson, Biological Rhythms, Encyclopedia of Nursing \& Allied Health, http://www.enotes.com/nursing-encyclopedia/biological-rhythm

Richardson, M.J., Marsh, K.L., Isenhower, R.W., Goodman, J.R.L., Schmidt, R.C., (2007). Rocking together: Dynamics of intentional and unintentional interpersonal coordination. Hum. Mov. Sci. 26, 867-891.

Schmidt, R., Carello, C., Turvey, M., (1990). Phase-transitions and critical fluctuations in the visual coordination of rhythmic movements between people. J. Exp. Psychol.- Hum. Percept. Perform. 16, $227-247$.

Shockley, K., Santana, M.-V., Fowler, C.A., (2003). Mutual Interpersonal Postural Constraints are involved in Cooperative Conversation. J. Exp. Psychol. 29, 326-332.

Will, U., Berg, E., (2007). Brain wave synchronization and entrainment to periodic acoustic stimuli. Neurosci. Lett. 424, $55-60$.

Table 1. The location and functions of the Cerebral Cortex

\begin{tabular}{|c|c|c|}
\hline Name & Location & Functions \\
\hline $\begin{array}{l}\text { Frontal } \\
\text { Lobe }\end{array}$ & $\begin{array}{l}\text { right under the } \\
\text { forehead }\end{array}$ & $\begin{array}{l}\text { How we initiate activity in response to our environment. } \\
\text { Judgments we make about what occurs in our daily activities. } \\
\text { Controls emotional response \& expressive language. } \\
\text { Memory for habits and motor activities. }\end{array}$ \\
\hline $\begin{array}{l}\text { Parietal } \\
\text { Lobe }\end{array}$ & $\begin{array}{l}\text { near the back } \\
\text { and top of the } \\
\text { head }\end{array}$ & $\begin{array}{l}\text { Location for visual attention } \& \text { touch perception. } \\
\text { Goal directed voluntary movements. } \\
\text { Manipulation of objects. } \\
\text { Integration of different senses. }\end{array}$ \\
\hline $\begin{array}{l}\text { Occipital } \\
\text { Lobes }\end{array}$ & $\begin{array}{l}\text { at the back of } \\
\text { the head }\end{array}$ & Vision. \\
\hline $\begin{array}{l}\text { Temporal } \\
\text { Lobes }\end{array}$ & $\begin{array}{l}\text { Side of head } \\
\text { above ears }\end{array}$ & $\begin{array}{l}\text { Hearing ability. } \\
\text { Memory acquisition. } \\
\text { Some visual perceptions. } \\
\text { Categorization of objects. }\end{array}$ \\
\hline
\end{tabular}


Table 2. The comparison of brainwaves

\begin{tabular}{|c|c|c|}
\hline Type & Frequency range & Usually associated with \\
\hline Delta & $0-4 \mathrm{~Hz}$ & $\begin{array}{l}\text { adults slow wave sleep } \\
\text { in babies }\end{array}$ \\
\hline Theta & $4-8 \mathrm{~Hz}$ & $\begin{array}{l}\text { young children } \\
\text { drowsiness or arousal in older children and adults }\end{array}$ \\
\hline Alpha & $8-12 \mathrm{~Hz}$ & $\begin{array}{l}\text { - } \quad \text { relaxed/reflecting } \\
\text { - } \text { closing the eyes }\end{array}$ \\
\hline Beta & $12-25 \mathrm{~Hz}$ & $\begin{array}{l}\text { - } \quad \text { alert/working } \\
\text { - } \text { active, busy or anxious thinking, active concentration }\end{array}$ \\
\hline Gamma & $25-100 \mathrm{~Hz}$ & certain cognitive or motor functions stress \\
\hline
\end{tabular}

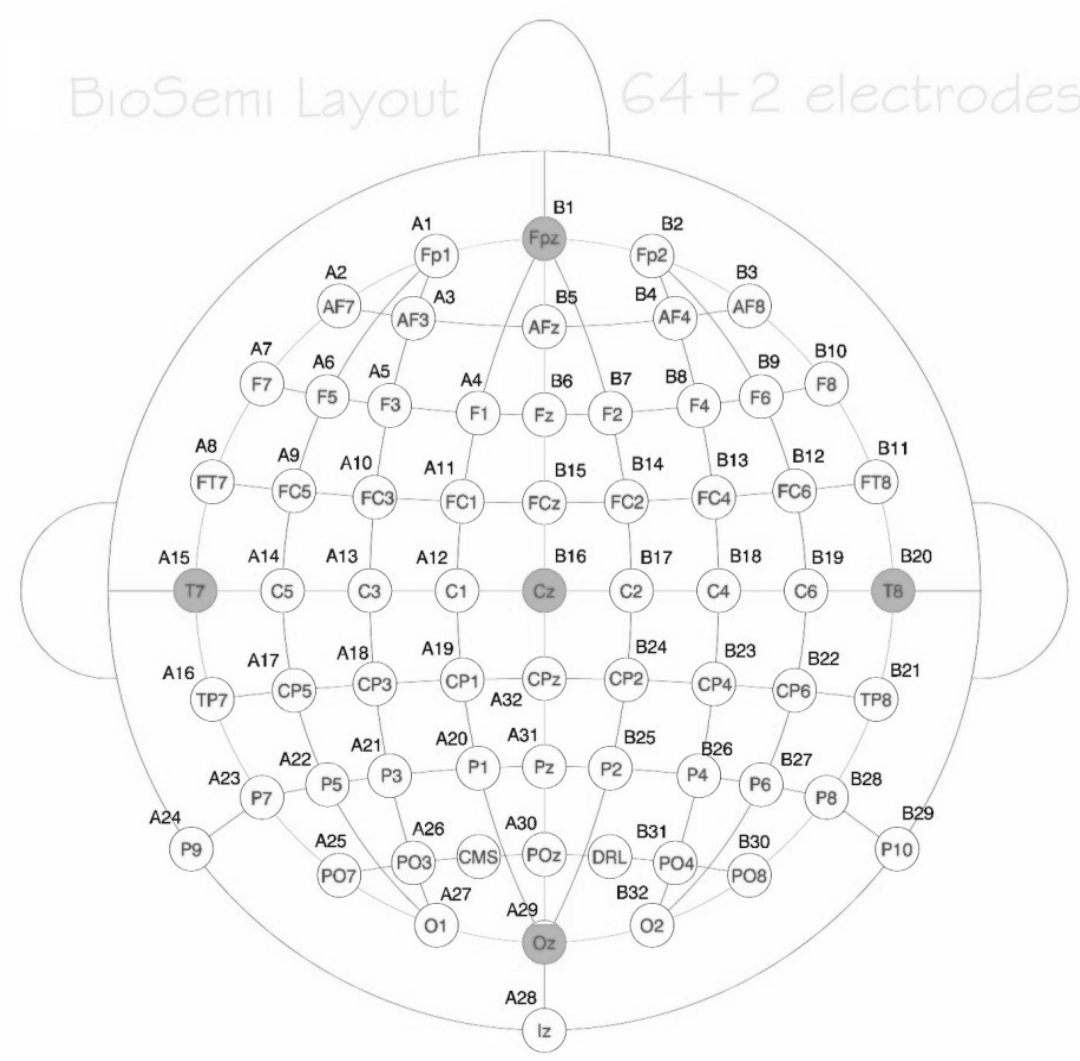

Figure 1. BioSemi Layout Electrodes System (64+2) 


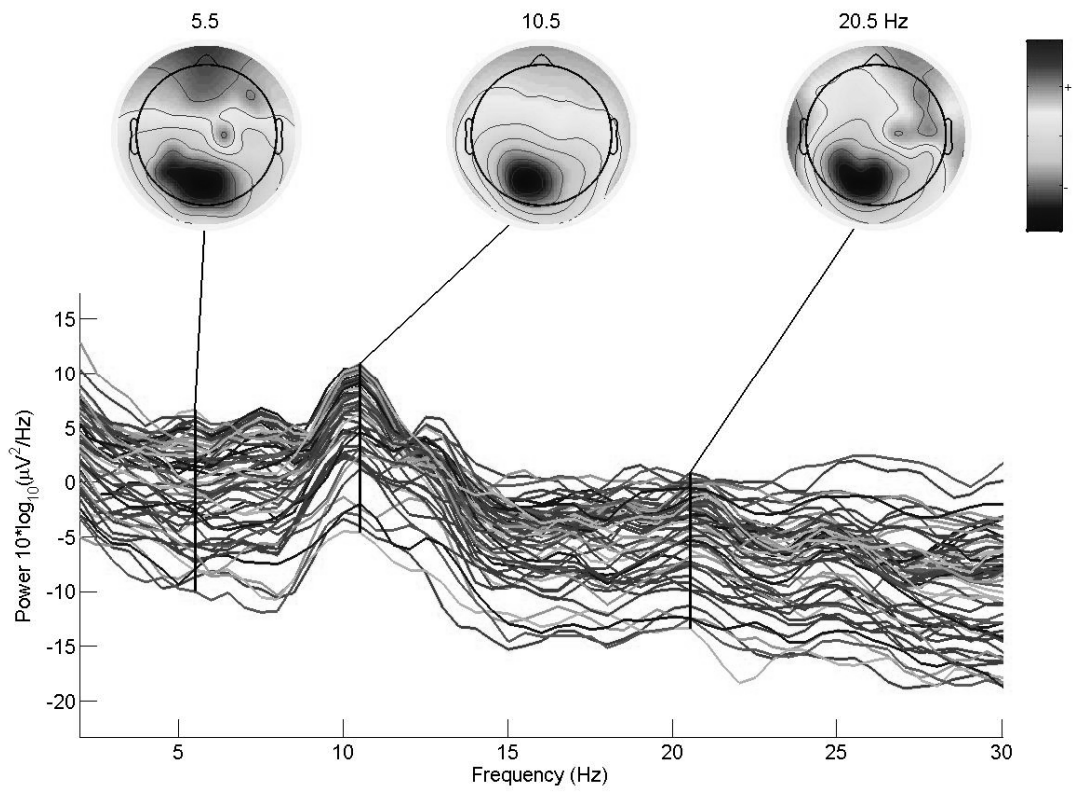

Figure 2. The distribution of power at $5.5 \mathrm{~Hz}, 10.5 \mathrm{~Hz}$ and $20.5 \mathrm{~Hz}$
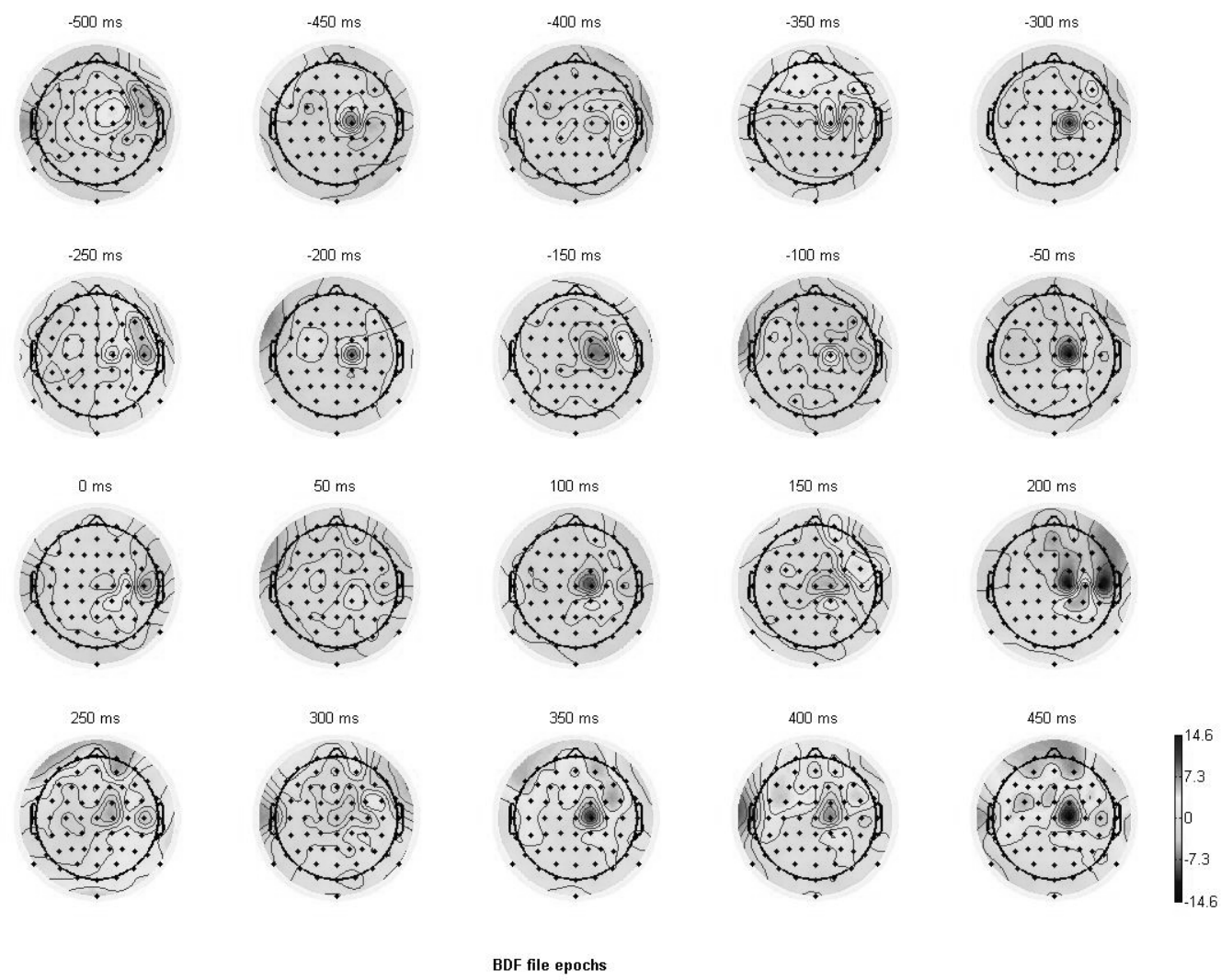

Figure 3. The details of ERP spectrum within one second 


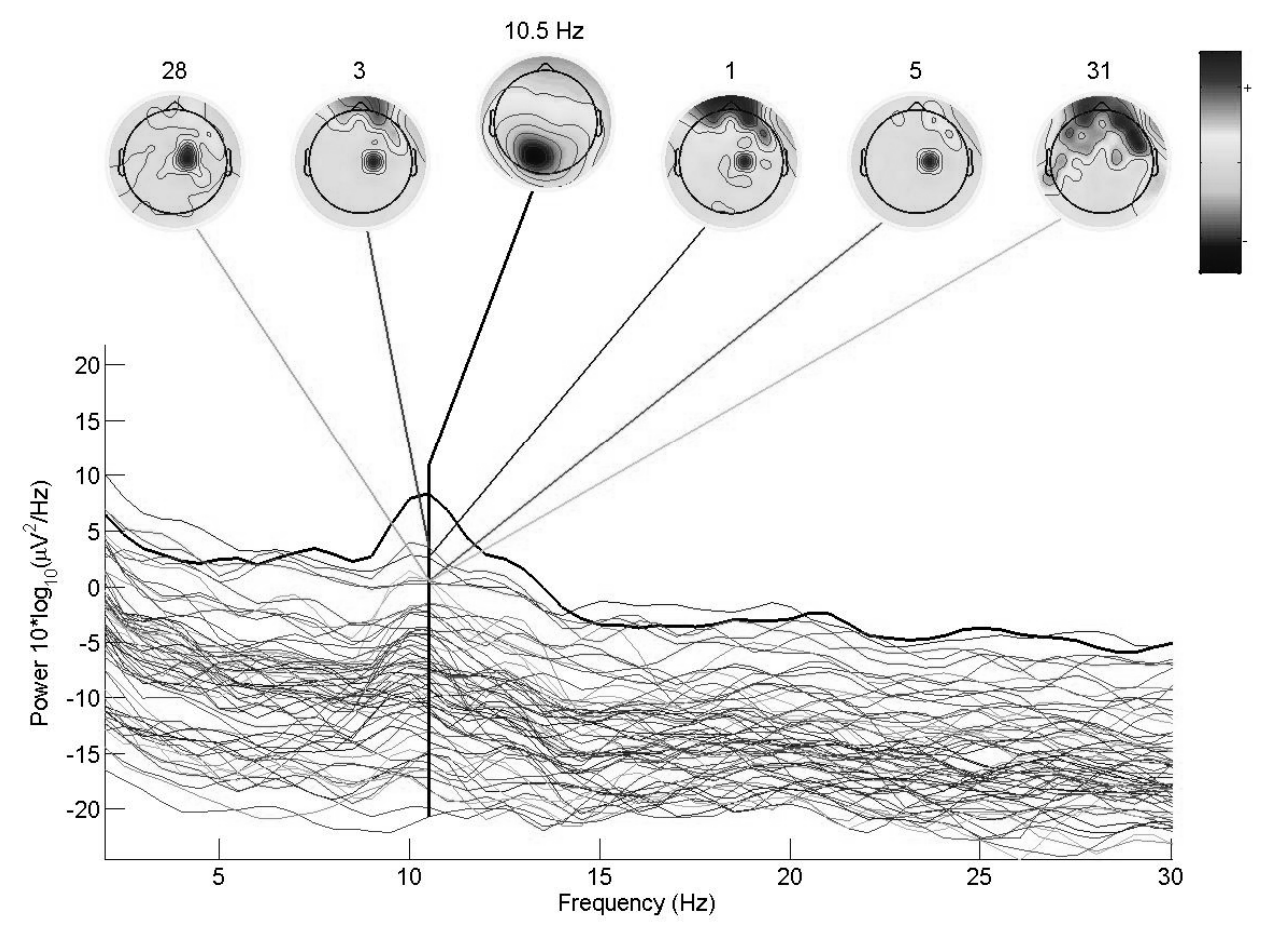

Figure 4. The spectra of each component 